\title{
Effects of stoping activities on tunnel conditions in a deep, hard rock mine in Austria
}

\author{
T. Ladinig, H. Wagner, and A. Daborer
}

Montanuniversitaet Leoben, Austria

\begin{abstract}
In a deep Austrian hard rock mine, the effect of stoping activities on a mine tunnel situated in the abutment area of a stoping panel, was investigated by means of underground observations and numerical modelling using FLAC 2D and 3D to assess the stress changes resulting from the advancing stopes. This paper discusses the difficulties encountered in quantifying in situ mechanical properties of sheared and jointed rock mass, numerical modelling of the complex geological conditions and relating calculated stress changes to in situ tunnel conditions. It was found that the rockwall condition factor ( $\mathrm{RCF}$ ) tunnel assessment criteria developed to evaluate tunnel conditions in deep South African gold mines, worked remarkably well under very different geological conditions. The focus of this paper is on the approaches adopted to deal with the uncertainties encountered in back analyses and case studies of situations involving behaviour of slender stope pillars, paste fill and regional effects of stoping activities on mine tunnels.
\end{abstract}

\section{INTRODUCTION}

The investigation was carried out in a small mine in the Eastern Alps, characterized by complex and variable geological conditions. In shallow mining areas up to a depth of about $700 \mathrm{~m}$ below surface, post pillar mining employing small square and rectangular pillars of heights of up to $100 \mathrm{~m}$ and mechanically placed backfill, was used to extract irregular mineral deposits. The use of backfill is necessary in the mine to minimize strata loosening and prevent flooding from water-bearing carbonatic rock formations in the overlying strata. At a mining depth of $700 \mathrm{~m}$ or greater, increased difficulties were encountered in terms of pillar stability and rock fall hazards associated with the upward progression of the $3.5 \mathrm{~m}$ high mining slices. Therefore, the post pillar mining method was replaced by a sublevel stoping system comprising $6 \mathrm{~m}$ wide and $21 \mathrm{~m}$ wide separated by continuous $7 \mathrm{~m}$ wide pillars. Cemented backfill was employed to stabilize the slender pillars and prevent uncontrolled strata movement. Depending on the vertical extension of the deposit, backfill was either placed up to the full stope height or up to the footwall level of the top drive. In the latter case, another stope was mined above the filled one and the unfilled top portion of the lower stope served as extraction drift. Panel pillars separated individual stopes and inter-panel pillars separated neighbouring mining panels (See Figure 1). Their purpose was to ensure that any vertical deformations were as small as possible. If not, then the soft and weak shale formation in which the mineral deposit is imbedded and which protects the mine against water-bearing limestone formations, might be disturbed and broken up. Another critical factor was the irregular geometry of the mineral deposit, which required great flexibility of the stoping system. These issues called for a thorough understanding of the rock mechanical behaviour in such a complex mining system. Therefore, an extensive rock monitoring programme accompanied the introduction of sublevel stoping. 


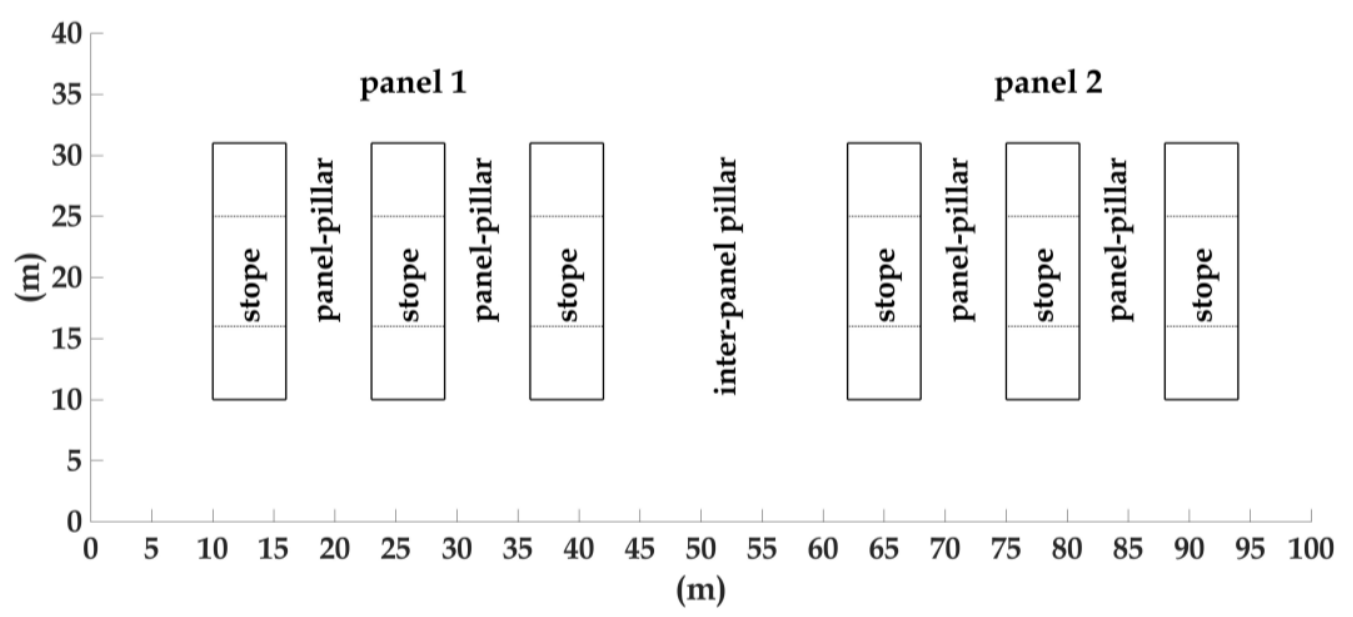

Figure 1. Vertical cross section perpendicular to the stope axes showing an inter-panel pillar between two neighboring mining panels

\section{ROCK MECHANICS INVESTIGATION PROGRAMME}

This paper deals with the effects of stoping activities on the behaviour of a mine tunnel outside the stoping area, and which was approached from the stopes. Deformations were monitored and the condition of the tunnel was investigated to understand the behaviour of slender stope pillars. In addition to analysing pillar behaviour, another objective of the study was to develop criteria and parameters for the design of deeper mining areas. Critical questions were the quantification of the mechanical properties of the rock mass and the development of practical and user friendly criteria for the design and support of the tunnel infrastructure.

\section{Description of the research area}

The research area was a single, isolated mining panel situated at a depth of $900 \mathrm{~m}$. It comprised six stopes and a mine tunnel situated in the abutment area. Figure 2 shows a vertical cross section through the panel. The stopes have a cross-section of $6 \mathrm{~m}$ in width and $21 \mathrm{~m}$ in height and $7 \mathrm{~m}$ wide panel pillars separating neighbouring stopes. The length of the stopes is $80 \mathrm{~m}$. A top and bottom drift of $6 \mathrm{~m}$ in width and $6 \mathrm{~m}$ in height is used to extract a stope. Both drifts were developed to the end of the stope. The formed sill pillar is extracted on the retreat by means of bench blasting. Backfilling took place immediately after a stope was mined out. Only one stope is mined in the panel at any point in time. In the event the deposit extended above the extracted stope, the backfill was only placed to the height of the former floor of the top drift. In the other instances, the stope is paste filled completely. During the research period, no stopes were extended to a second sublevel above. The mine tunnel, which serves as an access to the panel, was excavated before mining started and situated in the area to the right of the panel. It has a cross section of $6 \mathrm{~m}$ in width and $6 \mathrm{~m}$ in height. Mining commenced at the left-hand side with stope number 1, continued towards the mine tunnel and ended after stope number 6 was mined. In the final stage of stoping, a $7 \mathrm{~m}$ wide pillar separated the mine tunnel from the neighbouring stope, number 6 . This mining situation is ideally suited to investigate the effect of stress changes caused by the advancing stopes on tunnel conditions. The conditions were monitored using digital photo documentation at regular intervals and some extensometer measurements of rock deformation in the sidewalls of the tunnel. 


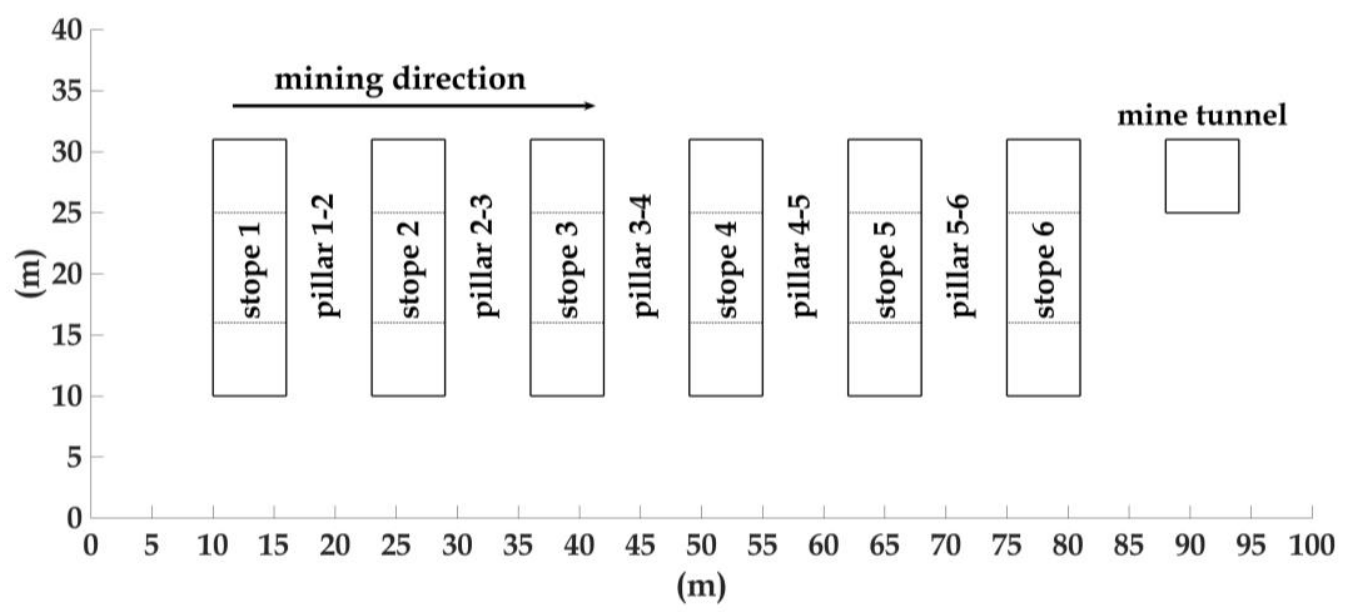

Figure 2. Vertical cross section perpendicular to the stope and tunnel axes of the research area.

\section{Rock stress environment}

The overburden of the research area is approximatively $900 \mathrm{~m}$. No stress measurements could be made due to a heavily disturbed rock mass. Single, isolated stress measurements are considered insufficient to describe the primary stress situation in the geological environment. While multiple stress measurements could have overcome this issue, they proved to be too costly. The primary rock stresses were estimated on the basis of the depth and an assumed average density of $2700 \mathrm{~kg} / \mathrm{m}^{3}$ of the overlying rock mass. Horizontal stress was assumed to fall in the range of 0.5 to 1.0 of the vertical stress, Brady and Brown (2004). As the mine is located in the Alpine region, significant tectonic stresses are usually present, justifying a wide range of horizontal stresses to assess their likely effect on results of stress analyses. Due to the nature of the deposit and its surrounding formations, the primary stresses had to be adjusted further. The deposit has a higher stiffness than the shales in the immediate foot- and hanging wall and is therefore comparable to a rigid inclusion. To quantify this effect, linear elastic numerical simulations were conducted. Details related to these simulations were not relevant to the investigations presented in this paper. However, based on the results of these simulations it was decided to conduct the analyses of the effect of stoping on the stress situation at the tunnel site with a hydrostatic stress of magnitude $28 \mathrm{MPa}$. This value accounts for the stress increases due to the effect of the rigid inclusion. Observations of conditions of isolated drifts at a depth of $900 \mathrm{~m}$ did not show any considerable amount of damage in the roof or sidewalls. Moreover, any differences in conditions between isolated drifts in striking direction and transverse direction, could not be identified. For these reasons, it was concluded that the assumption of a hydrostatic primary stress field was appropriate.

\section{Mechanical properties of the rock mass}

A comprehensive programme was conducted to determine the rock mass properties of the magnesite deposit. The programme comprised core drilling to determine rock quality designation (RQD) and obtain samples for subsequent laboratory tests to determine rock strength and elastic rock properties. In addition, joint mapping was carried out to determine the orientation and spacing of discontinuities and discontinuity properties such as joint roughness and joint persistence. Based on the investigations, different zones were identified within the magnesite deposit, namely zones of fairly massive unjointed rock, shear zones and several major faults. A specific feature of the deposit revealed that rock mass properties can change over relatively short distances. This makes predicting expected rock conditions difficult. For this reason, several rock mass classification systems were used, including Bieniawki's RMR, Bieniawski (1976), Hoek's geological strength index (GSI), Hoek et al. (2013) and Barton's Qsystem, Barton (2002) and Barton et al. (1974), to quantify rock mass conditions in the deposit.

Moser et al. (2017) report details of this rock mass classification programme. Rock mass property determination was based on the Hoek/ Brown generalized strength criteria, Hoek and Brown (1988) and Hoek et al. (2002) and the latest published version of the GSI system, Hoek et al. (2013). Observation 
points are typically $10 \mathrm{~m}$ apart, and GSI and rock mass strength values vary over short distances. This issue is a specific feature of many small Alpine mineral deposits and makes rock mass characterization very difficult. The GSI value for the area ranges from 45 to 75 with an average value of 65 . Uniaxial compressive strength of samples from the area ranges from $48 \mathrm{MPa}$ to $154 \mathrm{MPa}$ with an average strength of $110 \mathrm{MPa}$. Global rock mass strength based on Hoek/Brown general rock strength criterion, Hoek et al. (2002) ranges from $11 \mathrm{MPa}$ to $48 \mathrm{MPa}$. The average global rock mass strength is $27 \mathrm{MPa}$.

Compared to the assumed primary stresses of $28 \mathrm{MPa}$ and the conditions of isolated drifts, the global rock mass strength of $27 \mathrm{MPa}$ reported by Moser et al. (2017), appears to be too low. No significant amount of damage could be observed in isolated drifts. To clarify this discrepancy, the rock mass classification was reworked, using the latest version of Hoek's GSI, Hoek et al. (2013) and the global rock mass strength calculated after the Hoek/Brown generalized strength criteria, Hoek and Brown (1988) and Hoek et al. (2002). The results yield an average increase in the GSI values of 5 to 10 points. A multiple stage triaxial compressive strength test gave a $m_{i}$ - constant of 36 for the Hoek/Brown failure criteria in intact rock. This $m_{i}$-constant is considerably higher than the previously used $m_{i}-$ value of 9 , which was based on suggested ranges of $m_{i}$ - constants found in Marinos and Hoek (2000). The discrepancy in the $\mathrm{m}_{\mathrm{i}}$ - values demonstrates the importance of validating values for constants proposed in literature by observations and tests. Figure 3 shows the result of the reworked rock mass classification in the deep section of the mine. The reworked global rock mass strength after Hoek/Brown ranges from $36 \mathrm{MPa}$ to $67 \mathrm{MPa}$ with an average from $55 \mathrm{MPa}$ (See Figure 3).

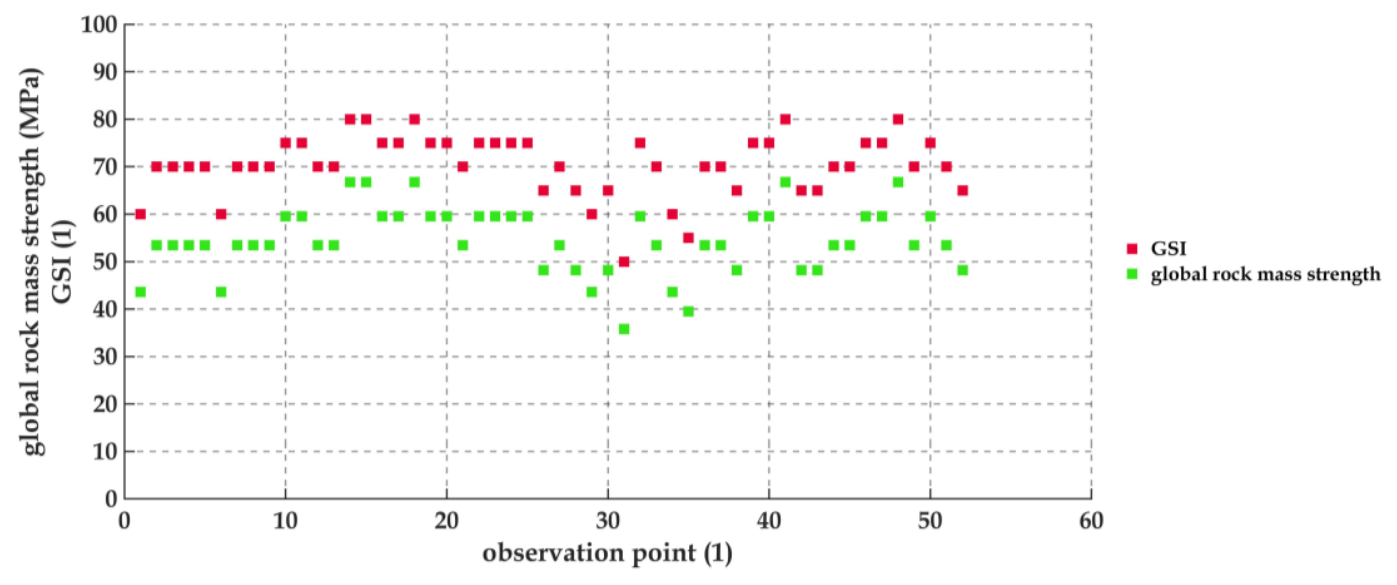

Figure 3. Reworked rock mass classification and rock mass strength values in deep portions of the mine.

In view of the considerable effort to determine the rock mass properties and the difficulty encountered in converting these properties into practical and easy to use design criteria, an attempt was made to use the concept of back analysis to develop practical design criteria for the siting and support of mine tunnels in this mine.

\section{THE USE OF BACK ANALYSES IN MINE DESIGN}

Back analysis is a powerful tool in rock engineering design of mines. Essentially, it consists of the systematic evaluation of rock conditions in mines using realistic models of the relevant physical processes. Well known and widely adopted examples of back analysis in mine design include the design procedures for coal pillars in South African and Australian coal mines, which are based on the systematic evaluation of failed and intact coal pillars using statistical methods, Salamon and Munro, (1967) , or the concept of energy release rate (ERR) to assess the rockburst hazard in South African gold mines, Cook et al. (1966) and Salamon (1984). 


\section{The Rockwall condition factor (RCF)}

The approach adopted in this study follows the concept of the rockwall condition factor (RCF). Wiseman (1979) of the Chamber of Mines research organization in South Africa, developed the concept. In a comprehensive survey of the conditions of many tens of kilometres of gold mine tunnels, Wiseman found that the conditions of the tunnels could be described with a simple equation comprising the maximum tangential stress acting at the wall of a circular tunnel and the compressive strength of the rock.

$$
R C F=\left(3^{*} \sigma_{1}-\sigma_{3}\right) /\left(F^{*} \sigma_{c}\right)
$$

The expression in the first bracket defines the maximum tangential stress acting in the wall of a circular tunnel as a function of the major and minor principal stresses, $\sigma_{1}$ and $\sigma_{3}$, acting normal to the tunnel. Therefore, $\sigma_{\mathrm{c}}$ is the uniaxial compressive strength of the rock and $\mathrm{F}$ is a factor to account for the rock mass properties. Figure 4 illustrates the relation between RCF and tunnel conditions as well as the effect of tunnel support on tunnel conditions.

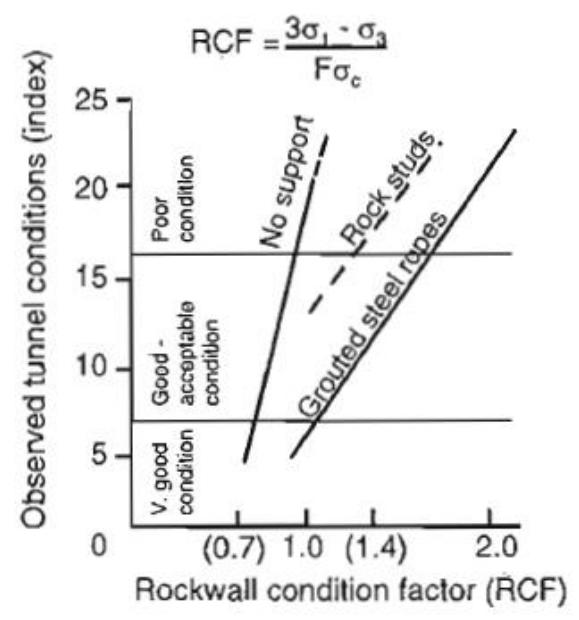

Figure 4. Relation of RCF, installed support and tunnel conditions (Jager and Ryder, 1999)

According to Figure 4, conditions in an unsupported tunnel are excellent in cases of a RCF $<0.7$, whereas in case of a RCF $>0.8$, the condition worsens rapidly and a high effort of support is required, Jager and Ryder (1999). The factor $\mathrm{F}$ describes the degree of degradation of rock strength due to jointing. According to Jager and Ryder (1999), $\mathrm{F}=1$ for a massive unjointed rock mass and reduces to $\mathrm{F}=0.5$ for an intensely jointed rock mass.

In the study reported here, the RCF concept has been modified slightly. Rather than using an analytical solution to determine the maximum tangential stress at the wall of a circular tunnel, the maximum tangential stress was calculated by numerical analyses which took into account the actual geometry of the tunnel. As this approach is comparable to the original RCF-concept (which takes also the maximum tangential stresses into account), it is referred to as modified-RCF (See equation 2). Furthermore, a distinction must be made between Modified-RCF values for the side and hanging wall of the tunnel. Tunnel conditions were monitored using digital photography at regular intervals. At selected points, up to three extensometers of different length were installed in boreholes located in the sidewall of the tunnel to determine rock deformation.

$$
\text { Modified-RCF }=\text { maximum modelled tangential stress } /\left(F^{*} \sigma_{c}\right)
$$




\section{Numerical simulation}

The mining geometry was simulated (See Figure 2), using FLAC 2D and FLAC 3D simulation programmes. Comparison of the results showed that in the middle portion of the $80 \mathrm{~m}$ long stopes, differences between the 2D and 3D simulations were very small. For this reason, only the 2D results are presented in this paper. We determined the stresses along lines at mid-height and mid-width of the tunnel shown in Figure 2 for each mining step. In contrast to the circular tunnel, the maximum vertical and horizontal stresses at mid-height and mid-width of the square tunnel did not occur at the tunnel wall but at some distance into the rock. The maximum vertical stresses at mid-height were used to calculate the Modified-RCF-value for the sidewall and the maximum horizontal stresses along the vertical line in the roof at mid-width of the tunnel to calculate the Modified-RCF-value for the tunnel roof. To determine the Modified-RFC-values, a rock strength of $110 \mathrm{MPa}$ and F-factors of 1, 0.75 and 0.5 were considered in the initial analyses.

The main difficulty encountered in this study was the assessment of the behaviour of the slender $7 \mathrm{~m}$ wide, $80 \mathrm{~m}$ long and $21 \mathrm{~m}$ high panel pillars. Because of the friable nature of the shale formation above and below the deposit, it was not possible to measure pillar stresses. Extensometer measurements of horizontal pillar deformation showed maximum lateral deformations of the $7 \mathrm{~m}$ wide pillars of up to $120 \mathrm{~mm}$. This deformation stopped once the room was backfilled. It was not possible to establish the effect of pumped backfill on pillar strength and deformation at this stage of the project. This issue will therefore be the subject of a new study. Moreover, the load and deformation behaviour of the pillar backfill system is not known, other than that regional pillar collapses were not observed in the past. Against this background of uncertainty, it was decided to model the following three situations:

- The extreme case of a system, where the pillars failed completely and have no residual strength and where the backfill does not carry any load, because it is not in contact with the overlying rock strata. This pillar-backfill system has zero stiffness,

- A system of failed pillars surrounded by pumped backfill with a low residual strength and a combined modulus of deformation of $0.5 \mathrm{GPa}$; and

- A pillar backfill system with a combined deformation modulus of $1 \mathrm{GPa}$.

Figure 5 summarizes the results of the numerical simulations. The Modified-RCF-values are based on an F-factor of $\mathrm{F}=0.5$ to account for the jointed rock mass.

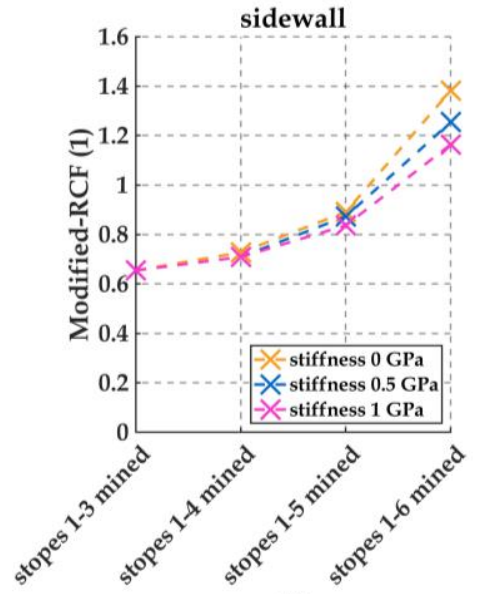

(a)

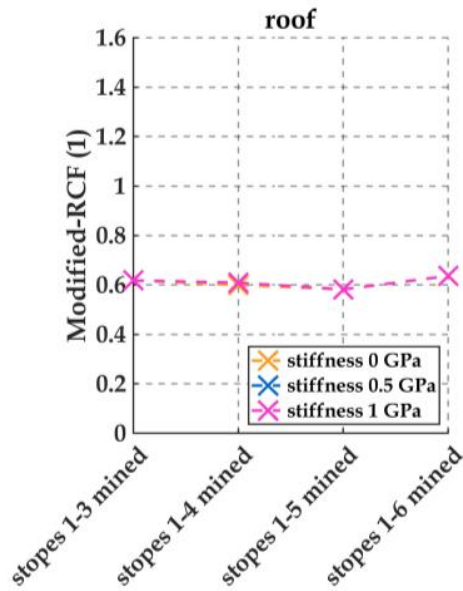

(b)

Figure 5. Effect of stoping activities and pillar-backfill stiffness properties on the Modified-RCF-values in the sidewalls and roof of the mine tunnel

Important results are that the stiffness properties of the pillar backfill system affected the rock stress environment of the mine tunnel only in the final stages of stoping activities. Extraction of the last stope 
in the mining panel resulted in a significant increase of the Modified-RCF-values in the sidewalls of the tunnel. The Modified-RCF-value of the roof of the square mine tunnel was virtually unaffected by stoping activities.

\section{Assessment of tunnel conditions}

The $6 \mathrm{~m}$ square mine tunnel was developed by conventional drilling and blasting ahead of the stoping activities to provide access to the stoping area. Except for occasional spot bolting using $3 \mathrm{~m}$ long mechanical end anchors to secure rock wedges formed by discontinuities, the tunnel was not supported. Once the area was prepared for stoping, the tunnel was required for ventilation purposes and also served as an escape route. Once stoping had been completed, the tunnel was no longer required and backfilled. Initial tunnel conditions were very favourable. A number of points along the mine tunnel were selected where digital photographs were taken at regular intervals. In the stoping area itself, a comprehensive rock mechanics measurement programme was established to assess the effectiveness of the backfill system, Moser (2018). The results of the numerical simulations were used to determine Modified-RCF-values for the different stages of the stoping and for different F-factors. The analyses showed that an F-value of $\mathrm{F}=0.5$ was the most appropriate strength adjustment factor. The comparison to the rock mass classification as previously described, shows, that downgrading the average rock strength of $110 \mathrm{MPa}$ by a F-value of $\mathrm{F}=0.5$ falls in the global rock mass strength range of $36 \mathrm{MPa}$ to 67 $\mathrm{MPa}$. This observation supported the analyses related to tunnel conditions. Table I shows the approach adopted to quantify the tunnel conditions based on our observational scheme.

Table I. Criteria used to quantify tunnel conditions based on visual observations.

\begin{tabular}{|l|l|}
\hline $\begin{array}{l}\text { Condition } \\
\text { rating (1) }\end{array}$ & Observed tunnel condition \\
\hline $1-1.5$ & Excellent tunnel conditions; solid tunnel walls; no support required \\
\hline $1.5-2$ & $\begin{array}{l}\text { See 1-1.5; tunnel walls with minor joints or fracturing; occasional spot bolting, where } \\
\text { required }\end{array}$ \\
\hline $2-2.5$ & $\begin{array}{l}\text { Tunnel walls with more fractures; compared to 1.5-2 more frequent spot bolting but no } \\
\text { systematic support pattern required; no signs of stress related fracturing or loosening }\end{array}$ \\
\hline $2.5-3$ & First signs of stress induced fracturing; limited strata loosening; isolated rock falls \\
\hline $3-3.5$ & $\begin{array}{l}\text { Signs of stress induced rock fracturing; strata loosening; isolated rock falls; introduction of } \\
\text { systematic support systems }\end{array}$ \\
\hline $3.5-4$ & $\begin{array}{l}\text { Increased signs of overstressing of tunnel walls; stress damage extends over larger areas of } \\
\text { tunnel walls; rock slabbing; formation of rock wedges between supports; visible signs of } \\
\text { strata loosening }\end{array}$ \\
\hline $4-4.5$ & $\begin{array}{l}\text { Marked signs of rock fracturing extending over full tunnel wall; formation of rock slabs; } \\
\text { local overstressing of support; high risk of rock falls from roof and sidewalls of tunnel; } \\
\text { tunnel no longer suited for normal operations; special precautions are necessary to enter } \\
\text { tunnel }\end{array}$ \\
\hline $4.5-5$ & $\begin{array}{l}\text { Tunnel in process of collapse; severe extent of fracturing and loosening; support has failed } \\
\text { largely; severe rock fall hazard }\end{array}$ \\
\hline
\end{tabular}

\section{Relationship of Modified-RCF and tunnel conditions}

Table II combines the results of the evaluation of mine tunnel conditions based on the numerically calculated stress changes caused by the stoping activities (See Figure 5), with the results of evaluation of tunnel conditions applying the methodology detailed in Table 1. 
Table II Relationship between Modified-RFC-values and conditions of mine tunnel under investigation

\begin{tabular}{|c|c|c|c|c|c|c|c|c|}
\hline $\begin{array}{l}\text { Condition } \\
\text { rating (1) }\end{array}$ & $\begin{array}{l}\text { Mod. - } \\
\text { RCF } \\
<0.7\end{array}$ & $\begin{array}{l}\text { Mod. - } \\
\text { RCF } \\
0.7-0.8\end{array}$ & $\begin{array}{l}\text { Mod. - } \\
\text { RCF } \\
0.8-0.9\end{array}$ & $\begin{array}{l}\text { Mod. - } \\
\text { RCF } \\
0.9-1\end{array}$ & $\begin{array}{l}\text { Mod. - } \\
\text { RCF } \\
1.0-1.1\end{array}$ & $\begin{array}{l}\text { Mod. - } \\
\text { RCF } \\
1.1-1.2\end{array}$ & $\begin{array}{l}\text { Mod. - } \\
\text { RCF } \\
1.2-1.3\end{array}$ & $\begin{array}{l}\text { Mod. - } \\
\text { RCF } \\
1.3-1.4\end{array}$ \\
\hline $1-1.5$ & XXX & & & & & & & \\
\hline $1.5-2$ & & $\mathrm{XXX}$ & $\mathrm{XXX}$ & & & & & \\
\hline $2-2.5$ & & XXX & & & & & & \\
\hline $2.5-3$ & & & & & & & & \\
\hline $3-3.5$ & & & & & & $\overline{X X X}$ & & \\
\hline $3.5-4$ & & & & & & & XXX & \\
\hline $4-4.5$ & & & & & & & XXX & XXX \\
\hline $4.5-5$ & & & & & & & & \\
\hline
\end{tabular}

The analysis of tunnel conditions using the Modified-RFC-concept yielded consistent results. With increasing Modified-RFC-values, the sidewall conditions of the tunnel deteriorate. The rate of deterioration is high above Modified-RCF-values $>1.1$. Roof conditions in the tunnel were excellent throughout the whole study. This observation is in agreement with the assessment of tunnel roof conditions based on the Modified-RFC concept.

\section{Assessment of state of panel pillars}

With regard to the numerical simulations of the stress environment in the vicinity of the mine tunnel, the difficulties relating to the assessment of strength and deformation behaviour of the slender panel pillars supported by backfill, were highlighted. From detailed studies of the post pillar mining systems in the shallower parts of the mine, it became known that very slender stope pillars imbedded in backfill cannot develop high strength values, but are capable of supporting the immediate roof strata. Therefore, the abutments of the stoping area carry the bulk of the overlying rock mass. The backfill prevents disintegration of the jointed slender pillars, ensuring their stable deformation which is essential for the success of post pillar mining systems, Blaha and Wagner (2013). The relationship between the ModifiedRFC-value and the tunnel conditions, which deteriorate rapidly at Modified-RFC-values above 1.1, support the assumption of a low pillar backfill system stiffness as the highest Modified-RFC-values are related to the pillar backfill systems with the lowest system stiffness.

Based on these observations, it can be concluded that the panel pillars, in a post-yield state of deformation, deform in a stable manner at relatively low stress level. A new experiment has been initiated to study this issue in greater detail. The important conclusion as far as overall mine stability is concerned, is that mining panel dimensions have to be limited by substantial inter-panel pillars between neighbouring mining panels. Present mine design is based on this concept.

\section{CONCLUSIONS}

The RCF-concept developed for the assessment of tunnel conditions and support requirements in deep gold mines in a slightly modified form (Modified-RCF-concept), has shown to be a suitable design tool for mine tunnels in deep Alpine mines. The main advantage of the RFC-design tool is its simplicity of use, and the small number of parameters required to apply it. Confidence in its applicability under complex geological conditions is likely to grow as more data becomes available. The design tool can also be used to evaluate the effectiveness of other mine design issues, such as pillar backfill systems. The results presented in this paper highlight the benefits that can be obtained from the systematic application of back analysis methods. 


\section{REFERENCES}

Barton, N., Lien, R. and Lunde, J. (1974). Engineering classification of rock masses for the design of tunnel support. Rock Mechanics, 6 (4), 189-239.

Barton, N. (2002). Some new Q-value correlations to assist in site characterisation and tunnel design. International Journal of Rock Mechanics and Mining Science, 39 (2), 185-216.

Bieniawski, Z.T. (1976). Rock mass classification in rock engineering. Exploration for rock engineering. Bieniawski Z.T. (ed.), 1, 97-106.

Blaha, H. and Wagner, H. (2013). Zur Frage der Belastung und Stabilität von Bergfesten im Hartgesteinsbergbau am Beispiel des „Post-Pillar“-Abbauverfahrens. BHM Berg- und Hüttenmännische Monatshefte, 158 (4), 121-129.

Brady, B.H.G. and Brown, E.T. (2004). Rock Mechanics for underground mining, $3^{\text {rd }}$ edn. Springer Science + Business Media.

Cook, N.G.W., Hoek, E., Pretorius, J.P.G., Ortlepp, W.D. and Salamon, M.D.G. (1966). Rock mechanics applied to the study of rockbursts. Journal of the South African Institute of Mining and Metallurgy, 66 (10), 436-528.

Hoek, E. and Brown, E.T. (1988). The Hoek-Brown failure criterion - a 1988 Update. Proceedings of 15th Can Rock Mechanics Symposium, University of Toronto Press: Toronto, 3-38.

Hoek, E. Carranza-Torres, C. Corkum, B. (2002). Hoek-Brown failure criterion - 2002 Edition. Proceedings 5th North American Rock Mechanics Symposium and 17th Tunnelling Association of Canada Conference, NARMS-TAC, Toronto, Hammah, R., Bawden, W., Curran, J. and Telsnicki M. (eds.). University Toronto Press: Toronto, 267-273.

Hoek, E. Carter, T.G. and Diederichs, M.S. (2013). Quantification of the Geological Strength Index chart. Paper presented at the 47th US Rock Mechanics /Geomechanics Symposium, San Francisco, CA, USA, June 23-26, 2013.

Jager, A.J. and Ryder, J.A. (1999). A handbook on rock engineering practice for tabular hard rock mines. The Safety in Mines Research Advisory Committee (SIMRAC), Johannesburg.

Marinos, P. and Hoek, E. (2000). GSI: A geologically friendly tool for rock mass strength estimation. Proceedings of the GeoEng 2000 Conference, Melbourne, Technomic Publishers Co Inc, Lancaster, 1422-1442

Moser, A. (2018). Backfill Systems. Research Project FFG No. 848616, FFG - Austrian Agency for Promotion of Industry related Research, Wien.

Moser, A. Wagner, H. and Schinagl, S. (2017). Application of rock mass classification systems as a tool for rock mass strength determination. Proceedings of the Eighth International Conference on Deep and High Stress Mining, Wesseloo J. (ed.), 28-30 March 2017, Australian Centre for Geomechanics, Perth, 569-585.

Salamon, M.D.G. (1984). Energy considerations in rock mechanics: fundamental results. Journal of the South African Institute of Mining and Metallurgy, 84 (8), 233-246.

Salamon, M.D.G. and Munro A.H. (1967). A study of the strength of coal pillars. Journal of the South African Institute of Mining and Metallurgy, 68 (2), 5567.

Wiseman, N. (1979). Factors effecting the design and conditions of mine tunnels. Research Report No. G01G10. Chamber of Mines Research Organization, Johannesburg, South Africa 


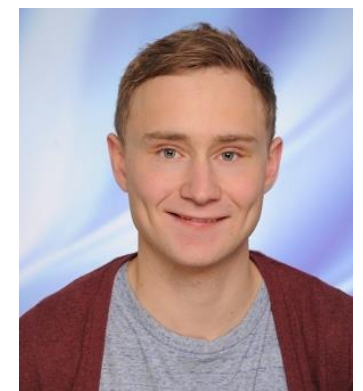

\section{Tobias Ladinig}

Research Assistant

Montanuniversitaet Leoben,

Chair of Mining Engineering and Mineral Economics

Qualifications: Mining rock mechanics, underground mining.

Study of mining engineering with focus on mining rock mechanics at Montanuniversitaet Leoben. Currently PhD-student of Prof. Wagner and research assistant at Chair of Mining Engineering. Focus on applied mining rock mechanics and underground mining systems from a rock mechanics point of view. 